\title{
On January 15 the Brazilian Journal of Geology will be part of the SciELO
}

By decision of the Brazilian SciELO Consultative Committee, as already stated in our editorial in edition 44(3), the Brazilian Journal of Geology (BJG) was deemed competent to be part of the Scientific Electronic Library Online (SciELO), which is considered the main virtual library of Brazilian scientific journals in the electronic format. SciELO mission is to organize and publish its material on the Internet thus offering to the best Brazilian scientific journals the possibility of sharing a common and advanced methodology in the creation of online scientific journals. For the Brazilian Journal of Geology, belonging to the SciELO means to use a platform that is similar to the Web-of-Knowledge of ThomsonReuters and to belong to the SciELO Citation Index. This will surely allow a radical increase of its accessibility and visibility in the scientific literature and will contribute to the increase of its impact.

One of the important advantages of belonging to the SciELO collection is our inclusion in the collection website, with visibility to open access users and also with the building of automatic indicators of use and impact. In this website, the Brazilian Journal of Geology may be searched by its title in a list with almost 300 journals and its articles may be accessed by author and/or subject in the classification of Exact and Earth Sciences.

In order to be part of the collection, SciELO requested us to complete an adhesion form with the contact data of the editor-in-chief, of the company encharged of sending the electronic files, basic information about the journal, its mission, the list of editorial board members, and instructions for authors. In addition, for the creation of the journal in the collection, SciELO requested us to send electronic files of the two most recent numbers of the journal, in XML format, according to the SciELO Publishing Schema. The adoption of XML format will be the second great advantage for the BJG because it enriches formatting, providing different kinds of presentation in the most diverse devices. Therefore, from the material in XML format, it is possible to create texts in HTML, PDF, EPUB, among others. The company in charge of the BJG secretariat has already provided SciELO with the material for numbers 44(2) and 44(3) of the Brazilian Journal of Geology in the XML format and is editing the most recent number 44(4) in the same format. Hence, SciELO has already confirmed the reception of the material and will proceed with the development of the journal in the collection on January 15, 2015. Our journal will be identified by the acronym BJGEO.

Finally, the third great advantage of being part of the SciELO collection will be using the editorial system ScholarOne, which belongs to ThomsonReuters, the most applied and complete online system for submission and evaluation of manuscripts. Besides creating PDFs for the reviewers and keeping a better and friendlier control of the entire pair-evaluation process, this system allows permanent acquisition of statistics on its functioning. Differently from the Open Journal System (OJS), which the journal is using at present, the ScholarOne is a paid system, however due to an agreement between SciELO and ThomsonReuters, for the journals that belong to SciELO, it is possible to use it without costs. Our secretariat is fully able to work with ScholarOne since the company that operates it is responsible for many journals operating it, inside the SciELO itself. For some time, the Brazilian Journal of Geology will work in parallel with both systems, the old (OJS) and the new one (ScholarOne), until all articles that are still under evaluation in the old system be processed to the end.

Umberto Giuseppe Cordani Editor in chief 
